(CASE REPORT)

\title{
Cure of immune thrombocytopenic purpura: A homeopathic approach
}

\author{
Yaseen Ghulam * \\ Saher Welfare Foundation 24-Allama Iqbal Road, Lahore Pakistan. \\ Publication history: Received on 28 February 2020; revised on 11 March 2020; accepted on 19 March 2020
}

Article DOI: https://doi.org/10.30574/gscbps.2020.10.3.0053

\begin{abstract}
Homeopathy can cure chronic disorders as well as multi-system syndromes. This is the most common alternative approach to treat cancers, allergies, psychological diseases, pain, and blood disorders. Immune thrombocytopenia (ITP) is an acquired hematological disorder characterized by low platelets count without any clinical cause. Platelets count $<100 \times 10^{9} / \mathrm{L}$ Is critical enough to confirm the diagnosis of Immune Thrombocytopenia. The significant cause of this increased consumption of platelets is low production in the bone marrow and high splenic sequestration. An acute case of ITP can be presented with severe nose and gums bleeding and petechiae on the body, clinically. Presented case report is of a 2 years old male child, pre-diagnosed case of immune thrombocytopenia, which was on corticosteroids from 6 months but his platelet count remained down as he left medicine. According to the constitution of the patient and pathogenesis of the disease, Belladonna 30c, Arnica 3x liquid form and Calcarea Phos 3x in powder form prescribed alternatively according to the symptoms. Presented case propose that homeopathic medicines have great efficacy to increase Hemoglobin level as well as platelets count.
\end{abstract}

Keywords: Immune Thrombocytopenia; ITP; Homeopathy; Idiopathic Thrombocytopenia

\section{Introduction}

Immune thrombocytopenic purpura was previously known as idiopathic thrombocytic purpura, due to the unknown cause. But, now this disease is no longer considered as idiopathic [1]. Accelerated platelet destruction and increased production of impaired platelets are the basic underlying cause for ITP. The normal range of platelets in a healthy person is from 150,000 to $450,000 / \mathrm{mm}^{3}$. As the values of platelets become less than $50,000 \mathrm{~mm}^{3}$, there may be a higher risk for the development of ITP. Platelets less than $20,000 \mathrm{~mm}^{3}$ can cause severe spontaneous bleeding $[2,3,4,5]$.

Immune thrombocytopenia is caused by the anti-platelet factor due to the destruction of platelets by the endothelial reticular system. It appears as an anti-platelet factor in many patients, as an IgG antibody binding towards a platelet associated antigen [6]. In ITP there are auto antibodies against platelets membrane glycoprotein that causes the antibody-mediated destruction and impaired production of platelets. Thrombopoietin (TPO) binds with its receptors present on the surface of hemopoietic stem cells and megakaryocytes. In patients of ITP, a slight elevation of TPO can be measured with low platelet count. Antibodies against TPO and platelets causes destruction and form impaired platelets in the low amount [7].

Thrombocytopenia can be acute or chronic. Usually, the case remains asymptomatic for a long time. Symptoms like bruises on the body, severe bleeding from gums and nose appear when platelets become very low. Mostly in cases of children, it is considered self-limiting [8]. Several therapies are considered to treat ITP effectively. High dose intravenous gamma globulin is effective in acute cases of ITP of childhood [9]. But it is assumed that splenectomy is the best and long-term treatment for ITP. The removal of spleen increases the risks of bacterial infections. Loss of muscle mass, osteoporosis, cataract, recurrent infections, and diabetes are major complications of ITP [4, 10, 11].

\footnotetext{
* Corresponding author: Yaseen Ghulam
} 


\section{Case presentation}

The patient was 2 years old male child, presented with red spots on the body, low appetite, and pain in legs, with a history of chest infection, treated by high doses of antibiotics. After the treatment of chest infection, red spots appeared on the body and there was a progressive decline in his health condition. On investigation, thrombocytopenia was confirmed. His platelet count was $40,000 \mathrm{~mm}^{3}$. His bone marrow reports showed peripheral thrombocytopenia with peripheral destruction and trilineage hematopoiesis with adequate numbers of megakaryocytes. The diagnosis was made 6 months back before homeopathic treatment. He was on corticosteroid therapy. His platelets increased to $674,000 \mathrm{~mm}^{3}$ in 15 days. His liver and abdomen became very hard and he was very uncomfortable. As the doctor cutoff steroids induction, platelets decreased to $10,000 \mathrm{~mm}^{3}$ in 2 months. After the failure of steroid therapy, he was referred to the homeopathic clinic. After detailed history taking and confirmation of the constitution following medicines prescribed. Table-1.

Table 1 (Prescription chart according to symptoms)

\begin{tabular}{|c|c|c|}
\hline Date & Symptoms & Medicines \\
\hline $3-2-2011$ & $\begin{array}{l}\text { Red spots on the whole body, bleeding from the nose, } \\
\text { Fatigue, low appetite, tenderness of liver whole abdomen } \\
\text { with hardness }\end{array}$ & Belladona 30 QID \\
\hline $13-4-2011$ & Red spots on arms and legs only, Low appetite, & $\begin{array}{l}\text { x-ray } 30 \text {, Belladona } 30 \text { TDS for a } \\
\text { month }\end{array}$ \\
\hline $11-5-2011$ & $\begin{array}{l}\text { Spots disappear, general health become well, low appetite, } \\
\text { the hardness of abdomen reduced }\end{array}$ & $\begin{array}{l}\text { China 3x liquid QID } \\
\text { Belladona } 30 \text { TDS }\end{array}$ \\
\hline $23-5-2011$ & $\begin{array}{l}\text { Pain in legs, sleep more due to fatigue, } 2 \text { spots on the right } \\
\text { leg, Appetite ok. }\end{array}$ & Arnica 3x and Calcarea Phos 3x QID \\
\hline $28-5-2011$ & $\begin{array}{l}\text { Red spots disappear, flu, chest congestion. } \\
\text { Platelets were normal. }\end{array}$ & $\begin{array}{l}\text { Allium cepa } 3 x \text { and } \\
\text { Gelsemium } 3 x \text { TDS for } 7 \text { days } \\
\text { Calcarea Phos 3x QID continued. }\end{array}$ \\
\hline $22-8-2011$ & $\begin{array}{l}\text { A blood test performed. Platelets were normal. Chest } \\
\text { infection cured. }\end{array}$ & Calcarea Phos 3x QID for a month. \\
\hline $24-9-2011$ & $\begin{array}{l}\text { Platelets count was in normal ranges. Apparently, he was in } \\
\text { normal condition. }\end{array}$ & $\begin{array}{l}\text { Bacillinum } 200,1 \text { dose given. } \\
\text { Advised for follow-up. }\end{array}$ \\
\hline
\end{tabular}

\section{Discussion}

The majority of children with Immune thrombocytopenia have a short duration of disease, but the quality of life reduce for a time and constant anxiety with fear of trauma can be observed in the families of such children. This is a self-limiting health condition mostly recovered in a few weeks but in 25-30 \% of children, this becomes chronic and develop many complications $[12,13]$. Corticosteroid therapy is assumed as the first line of treatment in all cases of ITP, but some patients do not respond to this treatment $[14,15]$.

In this case, the patient's recovery wasn't spontaneous. He was suffering from ITP from 6 months and was on corticosteroid therapy. Besides the treatment, his health condition wasn't stable. Homeopathic remedies can be considered complementary and alternative medicines to cure ITP. In this case report patient had a history of chest infection, subsequently Immune Thrombocytopenia was diagnosed. While treating through homeopathic medicines his chest infection appeared again and as it treated, ITP cured as well. There is no recurrence of ITP yet. Homeopathic remedies have great potential to cure acute and chronic disorders. It can enhance the quality of life and have the power to cure patients suffering from major disorders like cancers [16]. Individualized homeopathic medicines are more effective to treat blood disorders like ITP, Hemophilia and many others [17]. 


\section{Conclusion}

Immune thrombocytopenia and other blood disorders can be cured by homeopathic medicines effectively. Improvement in the health condition of the patient is significant and there is no recurrence after the homeopathic treatment. All cases in which ITP is not self-limiting and chronic disease cause complications; Homeopathic medicines can completely cure the disease and revive health. My case report suggests that classical homeopathic care is a compliment for every patient.

\section{Compliance with ethical standards}

\section{Acknowledgments}

Author is grateful to the family of patient.

\section{Disclosure of conflict of interest}

There is no conflict of interest

\section{Statement of ethical approval}

The present research work was approved by committee of Saher Welfare Foundation

\section{Statement of informed consent}

Informed consent was obtained from the parents of child.

\section{References}

[1] McCRAE K. (2012). Immune thrombocytopenia: No longer 'idiopathic'. Cleve Clin J Med, 358-373.

[2] PHB B.-M. (2000). Idiopathic thrombocytopenic purpura. Archives of Disease in Childhood, 220-222.

[3] James B, Bussel MD, Gregory Cheng, Mansoor N. Saleh, et al. (2007). Eltrombopag for the Treatment of Chronic Idiopathic Thrombocytopenic Purpura. N Engl J Med, 357, 2237-2247.

[4] Douglas BC and James BB.(2005). How I treat idiopathic thrombocytopenic purpura (ITP). Blood, 106, 22442251.

[5] Steen Rosthøj, Iris Hedlund-Treutiger, et al. (2003). Duration and morbidity of newly diagnosed idiopathic thrombocytopenic purpura in children: a prospective Nordic study of an unselected cohort. The Journal of Pediatrics, 143(3), 302-307.

[6] Robert McMillan M. (1981). Chronic Idiopathic Thrombocytopenic Purpura. N Engl J Med, 1135-1147.

[7] Takashi S, Koji M, Naoki S, et al. (2014). Detection of Anti-Thrombopoietin Antibodies in Patients with Immune Thrombocytopenia. Blood, 124, 4187.

[8] Craig M Kessler MM. (2018). Immune Thrombocytopenic Purpura (ITP).

[9] P Imbach V. (1981). HIGH-DOSE INTRAVENOUS GAMMAGLOBULIN FOR IDIOPATHIC THROMBOCYTOPENIC PURPURA IN CHILDHOOD. The Lancet, 1228-1231.

[10] Donahue M. (2018). Idiopathic Thrombocytopenic Purpura (ITP).

[11] Joseph Schwartz, Melissa D. Leber, Shmuel Gillis, et al. (2003). Long Term Follow-Up after Splenectomy Performed for Immune Thrombocytopenic Purpura (ITP). American Journal of Hematology, 72, 94-98.

[12] JoanneYacobovich SR.-V. (2013). Childhood Immune Thrombocytopenia Who Will Spontaneously Recover? Seminars in Hematology, S71-S74.

[13] Thomas Kühne MD, George R Buchanan MD, Sherri Zimmerman MD, et al. (2003). A prospective comparative study of 2540 infants and children with newly diagnosed idiopathic thrombocytopenic purpura (ITP) from the intercontinental childhood ITP study group. The Journal of Pediatrics, 143(5), 605-608. 
[14] MM A. (2014). Idiopathic thrombocytopenic purpura in children: a 10 years' experience at tertiary care hospital. J Pak Med Assoc, 1358-62.

[15] Yunfeng C, Raymond SM, Wong ChB, et al. (2003).Initial Treatment of Immune Thrombocytopenic Purpura with High-Dose Dexamethasone. N Engl J Med, 349, 831-836.

[16] Matthias Rostock JN. (2011). Classical homeopathy in the treatment of cancer patients - a prospective observational study of two independent cohorts. BMC Cancer, 11-19.

[17] Tapas Kundu AS. (2012). Homeopathic medicines substantially reduce the need for clotting factor concentrates in hemophilia patients: results of a blinded placebo-controlled cross over trial. Homeopathy, 38-43.

\section{How to cite this article}

Yaseen G. (2020). Cure of immune thrombocytopenic purpura: A homeopathic approach. GSC Biological and Pharmaceutical Sciences, 10(3), 85-88. 